The General Practitioner, the Psychiatrist, and the Burden of Mental Health Care.

Maudsley Discussion Paper No. 1. By DAVID

GOLDBERG \& KEVIN GOURNAY. London: Institute of Psychiatry. 1997. 31 pp. £2.95

The present inconsistencies in Government policies need to be addressed if mental health care is to be made as effective and efficient as possible. Take general practitioner (GP) referral to community psychiatric nurses (CPNs) as a case in point. In the 1996 Health of the Nation document Building Bridges the Government recommends that specialist mental health services should target first and foremost severely mentally ill people. This implies that CPNs should refuse referrals of less severely ill patients. On the other hand, the notion of a primary care led National Health Service, involving GP purchasing and commissioning, gives GPs greater access to CPN help with any patients they decide to refer for counselling.

This authoritative statement from the Institute of Psychiatry comes down firmly on the side of targeting specialist services, arguing that referral should be restricted to only those patients whose care demands a skill not available in the primary care team. CPNs should limit themselves to interventions shown to be effective with people with schizophrenia and other severe illnesses, such as specific psychological and family therapies. They suggest a great expansion in the numbers of general practice nurses who would carry out most treatment of patients with less severe illnesses, with the GP prescribing where indicated. Counsellors would be retrained if necessary, to offer proven treatments such as cognitive-behavioural therapy for depression. Non-specific support would be offered by generic mental health workers, perhaps in conjunction with voluntary organisations.

The paper is admirably clear and the authors cite more than 60 research studies to back their stance. However, I do think they have ignored some findings which do not support their case. For example, the paper fails to mention that the economic analysis of a controlled trial of referral to CPNs for less severe psychiatric problems did suggest that they might get patients back to work more quickly than GP care alone, which raises the question of whether CPNs would actually be more cost-effective if they treated more such patients. Also, it remains to be seen whether primary care nurses who have not chosen to train in mental health care will have the necessary attitudes and aptitudes. There is a need for further research in this area in my opinion.

The authors acknowledge the problems inherent in their proposals, especially the huge task of training large numbers of practice nurses and generic support workers. However, this paper represents an important challenge to policymakers at all levels to rationalise the division of mental health services between primary and secondary care, as a matter of urgency, through explicit referral criteria.

TONY KENDRICK, St George's Hospital Medical School, Cranmer Terrace, London SW17 ORE

\section{Disputed Confessions and the Criminal} Justice System. Maudsley Discussion Paper

No. 2. By GisLI H. GUDJONSSON \& JAMES

MACKerTH. London: Institute of Psychiatry. 1997. 20 pp. £2.95

Any psychiatrist or psychologist encountering the thorny issue of disputed confessions will reach with enthusiasm for a brief publication on the subject in the hope of obtaining some useful information and, more importantly, a guide on what to do. The authors bring the topic to life with reference to cases that have been in the public domain, such as the Birmingham Six. The need for caution in dealing with confessions made by individuals with a mental disorder is emphasised along with the change in legal and public attitudes to the possibility of a false confession. An approach to assessment is suggested by examination of (a) the circumstances surrounding a crime; (b) the interaction between interviewer and suspect; (c) the suspect's physical and mental health; and (d) the suspect's personality, incorporating assessment using a battery of tests including Gudjonsson's suggestibility and compliance scales. No exaggerated claims are made regarding the usefulness of these scales. It is noted that the presence of psychological vulnerabilities and mental disorder do not always invalidate a confession and that each case must be considered individually. Although, the paper describes the law as it pertains to England and Wales the points in the assessment process are valid elsewhere.

The paper concludes by raising the issue of the possible abuse of expert testimony in disputed confessions by defence lawyers and has strong words on the dubious practice in this area of some mental health professionals. While such practice may occur, evidence to support this was not cited. The authors end by stressing the need for balanced opinions and legal scrutiny. This publication is helpful in guiding the clinician in a methodical approach to assessment of disputed confessions.

LINDSAY D. G. THOMPSON, Department of Psychiatry, University of Edinburgh, Royal Edinburgh Hospital, Morningside Park, Edinburgh EH10 5HF 